\title{
LUNG GROWTH AFTER TRANSPLANTATION OF AN ADULT LOBE OF LUNG INTO A JUVENILE RAT
}

\author{
A. A. Hislop, $\mathrm{PhD}^{\mathrm{a}}$ \\ R. J. Lee, $M S^{\mathrm{b}}$ \\ C. G. A. McGregor, MB, FRCS ${ }^{\mathrm{b}}$ \\ S. G. Haworth, FRCP, FACC
}

\begin{abstract}
Objective: Shortage of donor organs for children has led to the use of living related adult lung lobar transplants. It is not known how these lobes or the recipient remaining lung grow after such transplants. The purpose of the present study was to assess lung growth in rat lungs up to 6 months after adult lobe transplantation into a juvenile recipient. Methods: Right cardiac lung lobes from adult male Lewis rats were transplanted into the left hemithorax of juvenile (6-week-old) male Lewis rats after left pneumonectomy. Animals with appropriate controls were put to death 14 days and 6 months after transplantation. The lungs were fixed inflated and studied by means of quantitative morphometric techniques. Results: By 6 months after transplantation both the recipient right lung and the transplanted cardiac lobe were significantly larger than normal $(p=0.005 ; p=0.001)$. In the recipient right lung this increase was due to an increase in the number of alveoli $(p=0.004)$ and in the transplanted cardiac lobe to an increase in size of the alveoli $(p=0.008)$. Conclusions: An adult lobe transplanted into a young recipient is still viable and has normal architecture after 6 months, and growth of the recipients' own lung continues. The outlook for comparable transplants in children is promising, although the human condition can be complicated by rejection, infection, and treatment strategies. (J Thorac Cardiovasc Surg 1998;115:644-51)
\end{abstract}

ung transplantation is an accepted treatment Loption for end-stage lung parenchymal and pulmonary vascular disease. However, the shortage of donor organs limits the use of this procedure. In children, living related donation has been successful in kidney, liver, and lung transplantation. The number of available donor lungs for children is even smaller than for adults, and the more extensive use of living related lobe donation would help ameliorate this organ shortage. Several animal models have been developed to study the problems of

From the Vascular Biology and Pharmacology Unit, Institute of Child Health, London, United Kingdom, ${ }^{\text {a }}$ and the Division of Cardiothoracic Transplantation, Mayo Clinic, Rochester, Minn. ${ }^{\text {b }}$

A. A. Hislop and S. G. Haworth are supported by The British Heart Foundation.

Received for publication Sept. 5, 1997; revisions requested Oct. 10, 1997; revisions received Nov. 6, 1997; accepted for publication Nov. 6, 1997.

Address for reprints: A. A. Hislop, PhD, Institute of Child Health, 30 Guilford St., London WC1N 1EH, United Kingdom.

Copyright (C) 1998 by Mosby, Inc.

$0022-5223 / 98 \$ 5.00+0 \quad \mathbf{1 2 / 1 / 8 7 5 2 9}$ surgical techniques and postoperative management of lung lobar transplantation ${ }^{1-3}$ but few studies have been conducted on the growth of the lungs, either in the donor or in the recipient lung. Kern and associates ${ }^{4}$ transplanted an adult lobe into a juvenile pig and showed normal growth in the recipient native lung and a normal appearance in the transplanted lobe 3 months after transplantation.

In a series of 20 patients receiving living related donor lobes, survival was $75 \%$ at 1 year, ${ }^{5}$ with the 10 pediatric patients surviving for up to 2 years. ${ }^{6}$ The long-term functional outcome of such patients is unknown. We have previously studied the growth of the immature transplanted rat lung after single lung transplantation. After transplantation of an immature donor lung into an immature recipient, both the transplanted lung and the native, recipient control lung continued to grow. ${ }^{7}$ Similarly, an immature lung transplanted into an adult rat also continued to develop normally, whether the strains used were isogeneic or allogeneic. ${ }^{8}$ In the present study, a right cardiac lobe of lung from a mature rat has been transplanted into an immature recipient rat that had undergone a left pneumonectomy. The growth of the transplanted lobe and the recipient right lung 


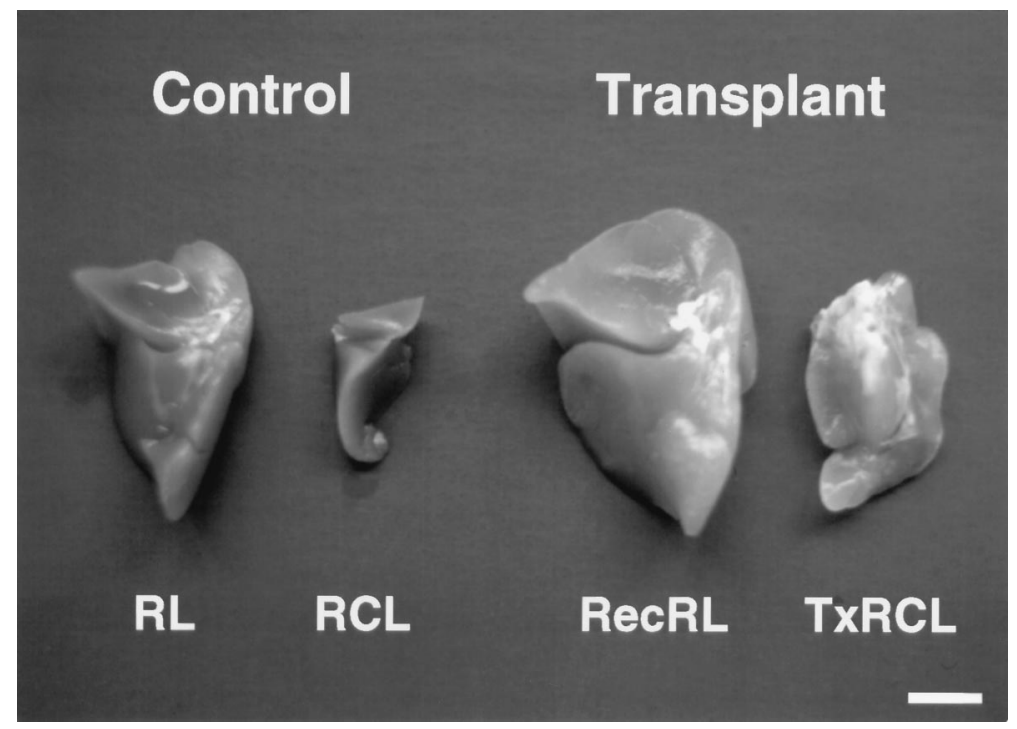

Fig. 1. Photograph of the right lung $(R L)$ and right cardiac lobe $(R C L)$ of a control rat aged 7.5 months and the recipient right lung (RecRL) and transplanted right cardiac lobe (TxRCL) 6 months after transplantation. Bar $=8.5 \mathrm{~mm}$.

has been assessed after 2 weeks and after 6 months by means of quantitative morphometric techniques.

\section{Material and methods}

Right cardiac lung lobes from 10 adult male Lewis rats (320 to $400 \mathrm{gm}$ ) were successfully transplanted into the left hemithorax of 6-week-old juvenile Lewis rats (120 to $150 \mathrm{gm})$ after left pneumonectomy. Animals were put to death 14 days $(n=4)$ and 6 months $(n=6)$ after the operation (mean weight $191 \mathrm{gm}$ and $424 \mathrm{gm}$, respectively). In addition, six juvenile Lewis rats underwent only a left pneumonectomy and were put to death 6 months after the operation. Control, unoperated rats of similar weight and age were also put to death $(n=10)$. All rats were purchased from Harlan Sprague Dawley, Inc., Indianapolis, Indiana. All animals have received humane care in compliance with the "Principles of Laboratory Animal Care" formulated by the National Society for Medical Research and the "Guide for the Care and Use of Laboratory Animals" prepared by the Institute of Laboratory Animal Resources and published by the National Institutes of Health (NIH Publication No. 86-23, revised 1985). The lobar transplant after an initial learning process was successful in $66 \%$ of cases. All animals with a left lung pneumonectomy survived.

Operative procedure. Donor rats were anesthetized with an intraperitoneal pentobarbital injection and their lungs were mechanically ventilated with room air. The thoracic organs were exposed through a median sternotomy and the right cardiac lobe artery, vein, and bronchus were dissected free to the base of the lung. Ties were placed around the venae cavae and ascending aorta. After full heparinization $(4 \mathrm{mg} / \mathrm{kg})$, these vessels were tied and divided. The lungs were then flush perfused with Marshall's solution (Baxters, Newbury, UK Ltd.) at $4^{\circ} \mathrm{C}$ via the right ventricle, with effluent flowing out through the amputated left atrial appendage. Ventilation was continued during perfusion and the trachea was ligated during expiration. The cardiac lobe bronchus was tied and the lobe separated from the rest of the lung block and stored in the perfusate at $4^{\circ} \mathrm{C}$. The right cardiac lobe is used for transplantation because it is easily separated from the rest of the right lung, having a complete pleural covering to the hilum. This lobe in the adult is similar in volume to the left lung of the immature rat.

The recipient rat was anesthetized by inhalation of a mixture of $60 \%$ oxygen, $40 \%$ nitrogen, and $4 \%$ halothane, intubated, and mechanically ventilated. The left side of the chest was opened through the fifth intercostal space and the left hilum was dissected free. After proximal clamping of the pulmonary vessels and ligation of the left main bronchus, a left pneumonectomy was performed. The donor right cardiac lobe was positioned in the left side of the chest so that the bronchial cartilage of the donor was juxtaposed to the membranous portion of the recipient bronchus. The pulmonary vein and artery were anastomosed by means of interrupted sutures for the front wall, allowing for future growth. The lung was reperfused, after which the bronchus was anastomosed by means of interrupted sutures. The chest wall was closed and a small chest drain left in situ, to be removed during recovery from anesthesia. Immediately after the operation a radiogram confirmed the correct positioning of the transplanted right cardiac lobe. The left pneumonectomy only group of animals were operated on by means of the same approach with ligation of the left main artery, vein, and bronchus.

Preparation of heart and lung tissue. At the end of the growth period the rats were weighed before lethal intraperitoneal injection of pentobarbital. The right and left 


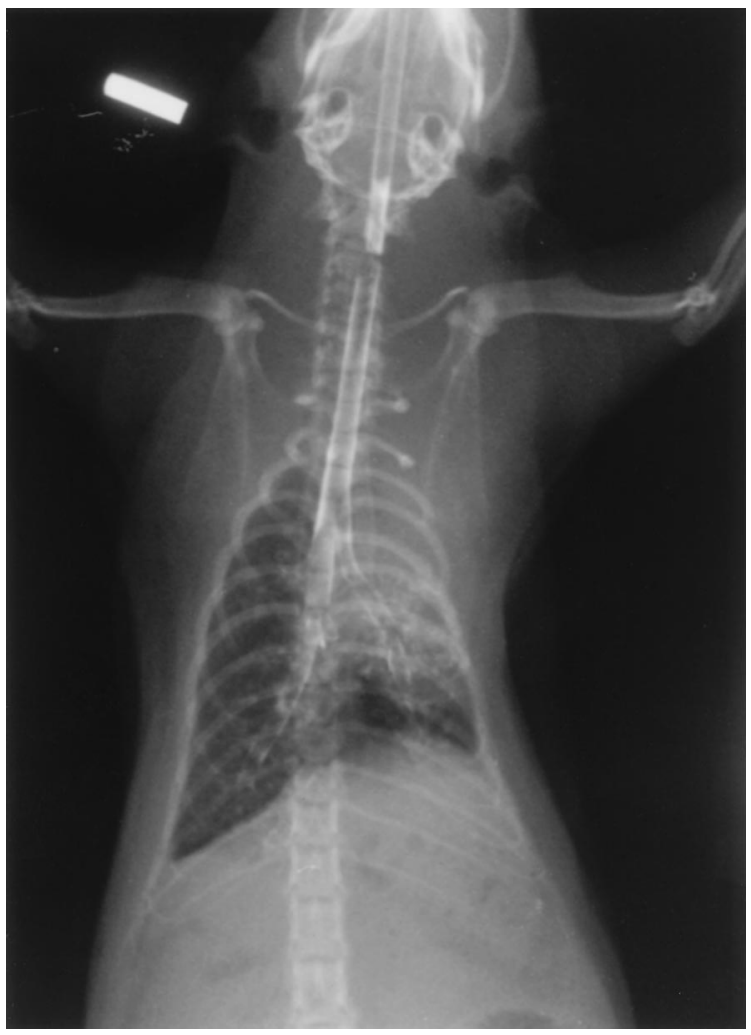

Fig. 2. X-ray film of adult rat with airways imaged after a bronchogram 6 months after transplantation. The right lung is displaced into the left hemithorax. All lobes were inflated with air.

lungs were simultaneously perfused through the main pulmonary artery and inflated through the trachea with $10 \%$ formaldehyde in buffered saline solution at a constant pressure of $30 \mathrm{~cm} \mathrm{H}_{2} \mathrm{O}$. The trachea was then tied off so that the lung was fixed inflated. After fixation the transplanted right cardiac lobe, the recipient right cardiac lobe, and the remaining three lobes of the recipient right lung were studied separately by means of quantitative morphologic techniques. Lobar volume was assessed by water displacement. The diameter of the bronchus at the hilum was measured with a dissecting microscope. Each lobe was then cut into $2 \mathrm{~mm}$ thick slices that were point-counted with a dissecting microscope and $1 \mathrm{~mm}$ grid. Point-counting separated discernible arteries and airways from the parenchyma, which is composed primarily of alveoli. Tissue sections were then processed through wax and $4 \mu \mathrm{m}$ sections cut and stained with hematoxylin and eosin or with Miller's elastic and van Gieson stain. Microscopic point-counts and alveolar counts were made and the total number of alveoli and the number per milliliter of alveolar region were calculated. ${ }^{7}$ The number per unit volume indicates alveolar size. The diameter of all terminal bronchioli in each section was measured. Pulmonary arterial thickness was measured and expressed as a percentage of external diameter:

\section{$2 \times$ Media wall thickness \\ External diameter $\times 100$}

Statistical analysis. The results for each structural feature for each lobe or lung in each experimental group and in each control group were compared by means of oneway analysis of variance. When appropriate, Student's $t$ test for unpaired data was used.

\section{Results}

Appearance of the lung. Six months after transplantation the recipient right lung and transplanted right cardiac lobe appeared larger than those of ageand weight-matched controls (Fig. 1). The right lung from the recipient rat was enlarged and the transplanted right cardiac lobe was considerably larger than normal and also had a less angular shape. The increase in size of the right recipient lung was apparent after only 14 days. Bronchograms after 6 months showed that all lobes were inflated, but the right lung was displaced into the left hemithorax (Fig. 2), and when the thorax was opened this was the disposition of the lungs. Microscopically, the transplanted lobe was seen to have a thickened pleura, but the airways, blood vessels, and alveoli were normal in structure. The alveoli appeared enlarged in comparison with normal alveoli (Fig. 3, $A$ and $C$ ).

The alveoli of the native recipient right lung appeared normal (Fig. 3, B). In the pneumonectomized animals the alveoli of the remaining lung were notably larger (Fig. 3, D).

Quantitative results. In control Lewis rats the lung volume increases with age. ${ }^{8}$ A similar increase was seen in the lungs of normal animals used as controls for the operated animals killed 14 days and 6 months after transplantation (Fig. 4, $A$ and $B)$. Fourteen days after lobar transplantation, the volume of the recipient right lung was already greater than in normal lungs of the same age. By 6 months after transplantation the volume of both the recipient right lung and right cardiac lobe was significantly greater than in controls of the same age ( $p=0.005$ and $p=0.009$, respectively). The combined volume of the recipient right lung and right cardiac lobe and the transplanted cardiac lobe was greater than the total lung volume (right and left lung) of control rats of the same age (10.1 vs $7.7 \mathrm{ml}, p=0.03)$. At this time the donor transplanted right cardiac lobe was also significantly larger than it was at the time of transplantation $(p=0.003)$ in comparison with agematched control animals. The volumes of the right 

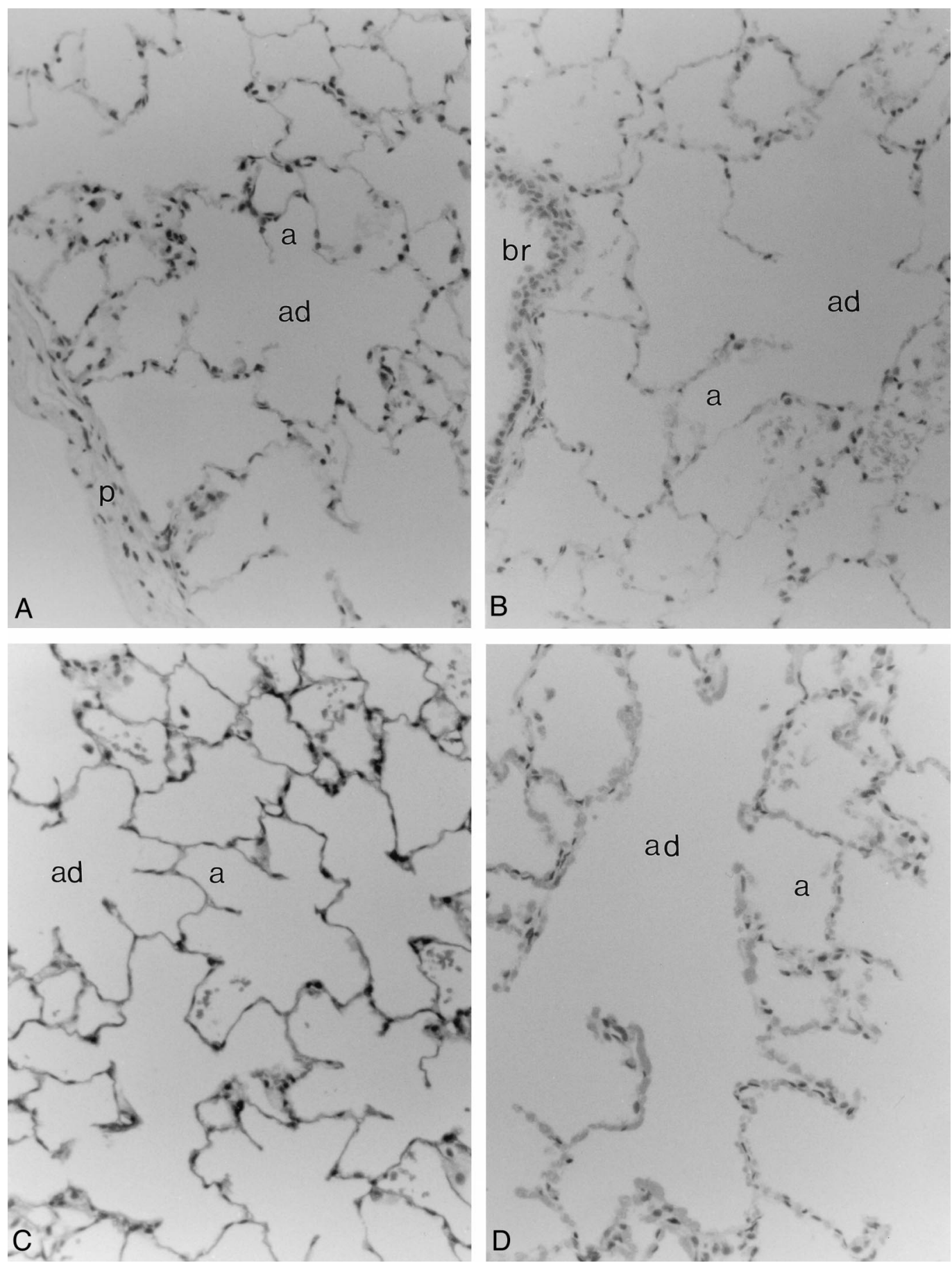

Fig. 3. Photomicrographs of the alveolar region: A, Transplanted right cardiac lobe 6 months after transplantation. B, Recipient right lung 6 months after transplantation. C, Control lung. D, Pneumonectomized lung. $a$, alveolus; $a d$, alveolar duct; $b r$, bronchiolus; $p$, pleura.

lung and right cardiac lobe of the animals after a left pneumonectomy were significantly larger than normal, and similar to the volume of the recipient right lung seen after transplantation.
Alveolar number and size. Six months after transplantation the alveolar number in the recipient native right lung was significantly greater than normal $(p=0.004)$, whereas in the transplanted cardiac 


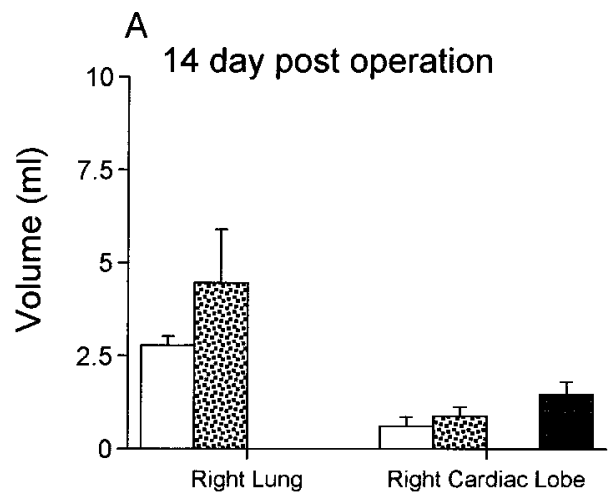

B

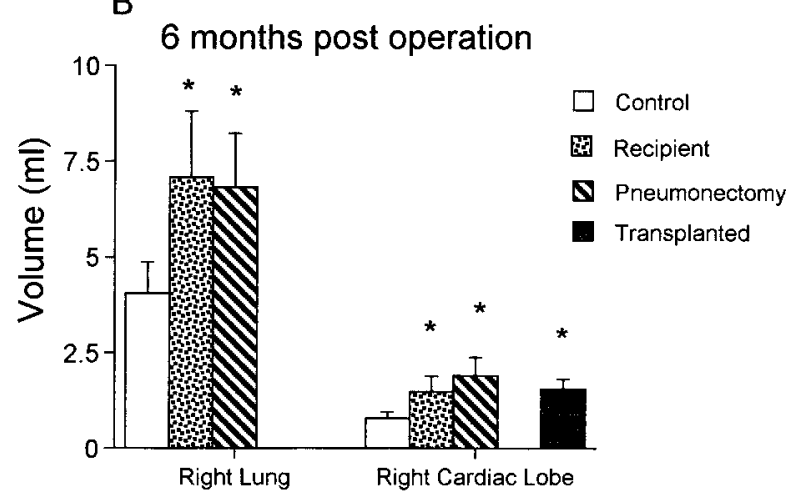

Fig. 4. Right lung and right cardiac lobe volume (A) 14 days and (B) 6 months after transplantation and pneumonectomy, together with control values. Mean and standard deviation. ${ }^{*} p<0.01$ in comparison with age-matched controls.

lobe alveolar number was normal (Fig. 5, A). In the lung after pneumonectomy the number of alveoli in the right lung, although increased, was not significantly different from either the control or the native recipient lung. Alveolar size determines the number of alveoli per milliliter, and values were normal in both the right lung and right cardiac lobe of the recipient, but the number per milliliter was significantly decreased in the transplanted cardiac lobe, indicating an increase in alveolar size $(p=0.008)$ (Fig. 5, B). After pneumonectomy, in the right lung the alveolar number per milliliter was decreased, significantly so in the cardiac lobe $(p=0.05)$.

Airway diameter. The diameter of the hilar airways was not increased after transplantation in either the transplanted or native recipient lung. By contrast, after pneumonectomy the diameters of the hilar bronchi of both the right lung and right cardiac

\section{A}
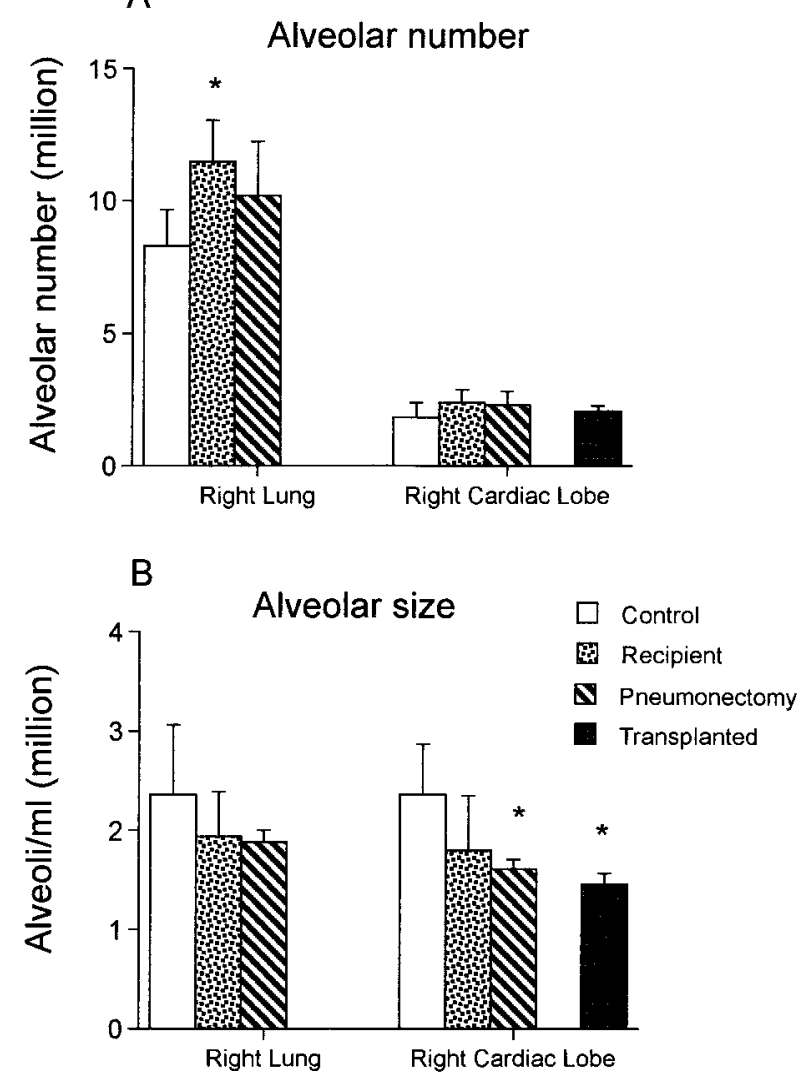

Fig. 5. Total alveolar number (A) and alveoli per milliliter (B) in the right lung and right cardiac lobe 6 months after the operation. ${ }^{*} p<0.01$ in comparison with control.

lobe were increased after 6 months (Fig. 6, $A$ ). Diameter of the terminal bronchioli was normal in all lungs (Fig. 6, B).

Pulmonary arterial medial thickness was normal in all cases (results not shown)

Summary of results. From this study it appears that an adult lobe transplanted into a juvenile recipient maintains its normal architecture and increases in volume by increasing alveolar size. Multiplication of alveoli was not excessive. The native lung of the recipient young rat continued to grow, producing normally formed alveoli and alveolar vessels; however, growth was excessive, the number of alveoli being increased together with some increase in their size. The changes seen in the remaining lung after left pneumonectomy alone were similar to those seen after transplantation, but less alveolar multiplication occurred and the alveoli showed a greater increase in size. 


\section{Discussion}

Much interest has been generated in the use of lobar or "reduced-size" adult lung transplants because of the shortage of donor organs in the pediatric age group. Experimental studies have shown that an adult lobe transplanted into an immature sheep, dog, or piglet survives well. ${ }^{1-3}$ Transplantation of mature lobes from pigs aged 3 months transplanted into neonatal piglets (aged 10 to 21 days) led, immediately after operation, to preferential ventilation of the adult lobe because of its greater compliance. ${ }^{9}$ An outcome study on young piglets aged 8 to 10 weeks at operation, and studied 12 weeks after transplantation, showed an increase in the volume of the adult transplanted lobe but no significant increase in alveolar number or size, suggesting growth of connective tissue and cellular components. ${ }^{4}$ By contrast, 6 months after transplantation of the adult cardiac lobe, we found that alveoli had increased in size, leading to an increase in lung volume.

Growth by increasing the size of existing alveoli has previously been described in the compensatory growth that occurs after pneumonectomy. ${ }^{10,11}$ In the present studies, the transplanted cardiac lobe was smaller than the normal left lung at the time of transplantation, and it increased in volume to fill the left hemithorax. In doing so it changed in shape. Lungs from children with scoliosis developing in later childhood have lungs of unusual shape. In children with cystic fibrosis who have undergone transplantation, the transplanted lung is overinflated because of the abnormal shape of the rib cage, but this does not appear to impair the function of this lobe. ${ }^{12}$

In the present study on rats, the native immature right lung increased in volume to become larger than normal, because of an increase in both alveolar size and number. Our previous studies on rats have shown that lung transplantation can disturb growth control in the contralateral, native lung of the recipient. When an immature left lung was transplanted into an immature rat (both syngeneic and allogeneic transplants), the number of alveoli in the native right lung was greater than normal only 2 weeks after transplantation and continued to increase, alveolar number still being greater than normal 6 months after transplantation. ${ }^{7}$ A similar response occurred in the native adult right lung 6 months after transplantation of an immature left lung (syngeneic and allogeneic). ${ }^{8}$ In the adult recipients, the transplanted immature left lung was obvi-
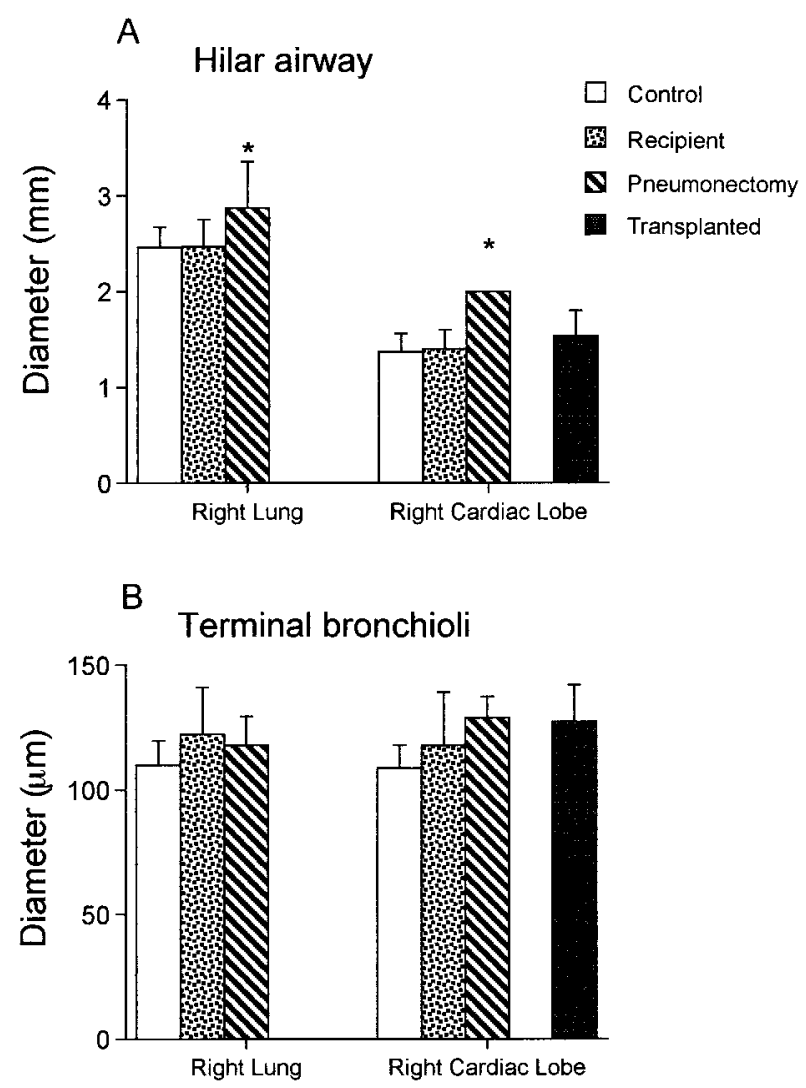

Fig. 6. Diameter of lobar bronchus (A) and terminal bronchioli (B) for the right lung and right cardiac lobe 6 months after the operation. ${ }^{*} p=0.05$ in comparison with control.

ously smaller than the excised lung; therefore one might expect compensatory growth. However, the average difference between the recipient and donor left lung volume of immature rats at the time of transplantation was only $0.8 \mathrm{ml}$, and in the present study the size differential between the removed left lung and the transplanted cardiac lobe was only 0.9 $\mathrm{ml}$. The increase in volume of the right lung 6 months after transplantation was 2 to $3 \mathrm{ml}$. Other investigations have shown that the compensatory growth that occurs when one or two lobes of the right lung are removed from a young animal is not excessive and results in a lung of normal volume for age. ${ }^{13,14}$ After a left pneumonectomy the right lung grows rapidly by increasing cell number and then alveolar structures until the total volume is sufficient to replace the resected tissue. ${ }^{15}$ However, in our studies on the transplanted rat lung, the right lung volume alone was similar to the total lung volume of 
normal animals. These observations suggest that after transplantation the right lung does not sense the presence of the denervated left lung or cardiac lobe. It is surprising that the right lung was not prevented from growing by the physical presence of the left lung. When inert material was left in the thorax after pneumonectomy in adult mice, the contralateral lung did not grow as rapidly as after pneumonectomy alone. ${ }^{16}$

In adult rats compensatory overgrowth after pneumonectomy is by increase in size of alveoli rather than number. ${ }^{10}$ In the present study, left lung pneumonectomy in young rats caused an increase in right lung volume owing to the combined increase in both the number and size of alveoli. Similarly, Holmes and Thurlbeck ${ }^{11}$ found that when pneumonectomy was carried out in 4-week-old rats the remaining lung grew by alveolar multiplication, but it grew by increase in alveolar size when the pneumonectomy was carried out at 12 weeks of age. These findings imply that there is a critical time period during postnatal development when alveolar multiplication can occur. Davies and associates,${ }^{17}$ in a study on the long-term outcome of pneumonectomy in 6- to 10-week-old dogs, found that the remaining young lung grew by an increase in alveolar number, but the final number achieved after 5 years did not exceed the normal adult number of alveoli for that lung, even though lung volume was increased. By contrast, in our transplantation studies on rats the increase in volume of the contralateral recipient lung of both juvenile and adult animals was caused by an increase in alveolar number, which exceeded normal, in addition to an abnormal increase in alveolar size. The mechanisms responsible for these changes are unknown.

In rats receiving an allogeneic transplant that atrophied soon after the operation, effectively producing a pneumonectomy, the remaining right lung enlarged by excessive alveolar multiplication. ${ }^{7}$ This was a much greater response than was seen after the standard pneumonectomy carried out in the present study. Other studies also showed that the overgrowth of the right lung could be explained only in terms of transplantation and was not due either to denervation or to inadvertent narrowing of the airway or to vascular stenosis of the transplanted left lung, causing a disproportionate flow of air or blood to the right lung. ${ }^{14}$ In both growing and adult recipients the increase in right lung volume has been seen after both syngeneic and allogeneic transplants, suggesting that this is not an immune response.
Thus it appears that transplantation alone has stimulated excessive growth, suggesting inappropriate epithelial and mesenchymal responses. In vitro studies suggest that proliferation of cultured epithelial cells involves activation by insulin-like growth factor-1 or by epidermal growth factor (EGF) functioning with transforming growth factor- $\alpha$ (TGF$\alpha) .{ }^{18}$ Optimal growth of tracheobronchial epithelial cells depends on the presence of EGF and TGF- $\alpha$ in the medium. ${ }^{19}$ These cells also synthesize and secrete TGF- $\alpha$ such that there is a degree of autoregulation. ${ }^{18}$ EGF also accelerates maturation of the alveolar epithelium. ${ }^{20}$ By contrast, TGF- $\beta$ is a powerful inhibitor of epithelial cell multiplication, ${ }^{21}$ but its presence leads to an increase in protein synthesis. ${ }^{22}$ It appears that the balance between TGF- $\beta$ and TGF- $\alpha$ and EGF may maintain the lung in the normal state of cell multiplication and differentiation once growth is complete. Studies on the unilateral transplanted rat lung suggest that this balance may be disturbed in the contralateral recipient lung. The findings suggest that growth factor production by one lung can affect the growth of the other, and therefore studies on the expression of lung growth factors in this experimental model may help elucidate the more general principles determining control of lung growth.

Recent studies showed that cold preservation and reimplantation of the rat lung causes an increase in the number of basal cells in the epithelium of the peripheral airways. ${ }^{23}$ This damage seemed irreversible, because it was maintained for up to 6 months after transplantation. This increase in basal cell number was associated with overgrowth of the airway wall and lumen. A single insult may therefore have a long-term effect on both airway and alveolar development. Cyclosporine (INN: ciclosporin) treatment may affect lung development but generally suppresses growth. In experimental animals, high doses of cyclosporine suppress total body growth $^{24}$ and can also reduce the multiplication of aortic medial smooth muscle and endothelial cells. ${ }^{25}$ However, we found that rats receiving transplanted lungs, which were not treated with cyclosporine, also had abnormally large native lungs. Treatment by artificial ventilation or steroids may also affect lung growth. In infants the use of glucocorticoids enhances the maturation of alveoli and prevents inflammation, ${ }^{26}$ but when glucocorticoids were given to rats postnatally, alveolar multiplication was inhibited $^{27}$ and glucocorticoids given in the presence of a high oxygen tension had a greater inhibitory affect. ${ }^{28}$ 
Treatment with high oxygen tensions alone reduces alveolar septation in newborn rats $^{29}$ and also increases airway smooth muscle and hyperresponsiveness. ${ }^{30}$

In conclusion, it would appear that an adult lobe transplanted into a young recipient is still viable after 6 months and that growth of the recipient's own lung continues normally. Clinical lung transplantation, however, is complicated by rejection, infection, and treatment strategies that may compromise lung development to a much greater extent than transplantation itself.

\section{REFERENCES}

1. Lillehei CW, Everts E, Shamberger RC. Reduced-size lung transplantation from adult to neonatal sheep. J Pediatr Surg 1992;27:1153-6.

2. Backer CL, Ohtake S, Zales VR, LoCicero J, Michaelis LL, Idriss FS. Living-related lobar lung transplantation in beagle puppies. J Pediatr Surg 1991;26:429-32.

3. Crombleholme TM, Adzick NS, Longaker MT, et al. Reduced-size lung transplantation in neonatal swine: technique and short-term physiological response. Ann Thorac Surg 1990;49:55-60.

4. Kern JA, Tribble CG, Flanagan TL, et al. Growth potential of porcine reduced-size mature pulmonary lobar transplants. J Thorac Cardiovasc Surg 1992;104:1329-32.

5. Barr ML, Schenkel FA, Cohen RG, et al. Bilateral lobar transplantation utilizing living related donors. Artif Organs 1996;20:1110-1.

6. Starnes VA, Barr ML, Cohen RG, et al. Living donor lobar lung transplantation experience: intermediate results. J Thorac Cardiovasc Surg 1996;112:1284-90.

7. Hislop AA, Odom NJ, McGregor CGA, Haworth SG. Growth potential of the immature transplanted lung: an experimental study. J Thorac Cardiovasc Surg 1990;100:36070.

8. Hislop AA, Rinaldi M, Lee R, McGregor CGA, Haworth SG. Growth of the immature lung transplanted into an adult recipient. Am J Physiol 1993;264:L60-5.

9. Crombleholme TM, Adzick NS, Hardy K, et al. Pulmonary lobar transplantation in neonatal swine: a model for treatment of congenital diaphragmatic hernia. J Pediatr Surg 1990;25:11-8.

10. Buhain WJ, Brody JS. Compensatory growth of the lung following pneumonectomy. J Appl Physiol 1973;35:898-902.

11. Holmes CWM, Thurlbeck WM. Normal lung growth and response after pneumonectomy in the rat at various ages. Am Rev Respir Dis 1979;120:1125-36.

12. Guignon I, Cassart M, Genenois PA, et al. Persistent hyperinflation after heart-lung transplantation for cystic fibrosis. Am J Respir Crit Care Med 1995;151:534-40.

13. Burri PH, Sehovic S. The adaptive response of the rat lung after bilobectomy. Am Rev Respir Dis 1979;119:769-77.
14. Rinaldi M, Hislop AA, Odom NJ, Haworth SG, McGregor CGA. Surgical factors affecting growth potential of the immature rat lung. Eur J Cardiothorac Surg 1991;5:218-22.

15. Brody JS. Time course of and stimuli to compensatory growth of the lung after pneumonectomy. J Clin Invest 1975;56:897-904.

16. Brody JS, Burki R, Kaplan N. Deoxyribonucleic acid synthesis in lung cells during compensatory lung growth after pneumonectomy. Am Rev Respir Dis 1978;117:307-16.

17. Davies P, McBride J, Murray GF, Wilcox BR, Shallal JA, Reid L. Structural changes in the canine lung and pulmonary arteries after pneumonectomy. J Appl Physiol 1982;53:85964.

18. Jetten AM. Growth and differentiation factors in tracheobronchial epithelium. Am J Physiol 1991;260:L361-73.

19. Thomassen DG, Saffiotti U, Kaighn ME. Clonal proliferation of rat tracheal epithelial cells in serum-free medium and their responses to hormones, growth factor and carcinogens. Carcinogenesis 1986;7:2033-9.

20. Sundell HW, Grey ME, Serenius FS, Escobedo MB, Stahlman MT. Effects of epidermal growth factor on lung malformation in fetal lambs. Am J Pathol 1980;100:707-26.

21. Jetten AM, Shirley JE, Stoner G. Regulation of proliferation and differentiation of respiratory tract epithelial cells by TGF- $\beta$. Exp Cell Res 1986;147:539-49.

22. DiMari SJ, Howe AM, Haralson MA. Effect of transforming growth factor- $\beta$ on collagen synthesis by fetal rat lung epithelial cells. Am J Respir Mol Biol 1991;4:455-62.

23. Huntley AL, Hall SM, Hislop AA, Odom N, McGregor CGA, Haworth SG. Airway structure following preservation and transplantation in the unilateral transplanted rat lung model [abstract]. Am Rev Respir Dis 1993;147:A261.

24. Thomson AW, Whiting PH, Blair JT, Davidson RJL, Simpson JG. Pathological changes developing in the rat during a 3 weeks' course of high dosage cyclosporin A and their reversal following drug withdrawal. Transplantation 1981;32:271-7.

25. Ferns G, Reidy M, Russell R. Vascular effects of cyclosporin A in vivo and in vitro. Am J Pathol 1990;137:403-13.

26. Yoder MCJ, Chua R, Tepper R. Effect of dexamethasone on pulmonary inflammation and pulmonary function of ventilator-dependent infants with bronchopulmonary dysplasia. Am Rev Respir Dis 1991;143:1044-8.

27. Tschanz SA, Damke BM, Burri PH. Influence of postnatally administered glucocorticoids on rat lung growth. Biol Neonate 1995;68:229-45.

28. Thibault DW, Heimes B, Rezaiekhaligh M, Mabry S. Chronic modifications of lung and heart development in glucocorticoid-treated newborn rats exposed to hyperoxia or room air. Paediatr Pulmonol 1993;16:81-8.

29. Han RNN, Buch S, Tseu I, et al. Changes in structure, mechanics, and insulin-like growth factor-related gene expression in the lungs of newborn: rats exposed to air or $60 \%$ oxygen. Pediatr Res 1996;39:921-9.

30. Hershenson MB, Garland A, Kelleher MD, Zimmermann A, Hernandez C, Solway J. Hyperoxia-induced airway remodelling in immature rats: correlation with airway responsiveness. Am Rev Respir Dis 1992;146:1294-300. 